\begin{tabular}{|l|c|}
\hline $\begin{array}{l}\text { ACCESOS TOTALES AL SERVIDOR } \\
\text { DESDE SU INICIO }\end{array}$ & 514.925 \\
\hline ACCESOS EN 1997 & 36.451 \\
\hline ACCESOS EN 1998 & 126.196 \\
\hline ACCESOS EN 1999 & 352.298 \\
\hline $\begin{array}{l}\text { SEMANA DEL AÑO 1999 CON MÁS ACCESOS: } \\
\text { 27/9-4/1 }\end{array}$ & 22.065 \\
\hline $\begin{array}{l}\text { SEMANA DEL AÑO 1999 CON MENOS ACCESOS: } \\
\text { 18/1-25/1 }\end{array}$ & 783 \\
\hline $\begin{array}{l}\text { DÍA DE LA SEMANA CON MÁS VISITAS DESDE } \\
\text { EL INICIO DEL SERVIDOR: MIÉRCOLES }\end{array}$ & 189.074 \\
\hline $\begin{array}{l}\text { DÍA DE LA SEMANA CON MENOS VISITAS } \\
\text { DESDE EL INICIO DEL SERVIDOR: SÁBADO }\end{array}$ & \\
\hline $\begin{array}{l}\text { DÍA DEL AÑO CON MÁS ACCESOS } \\
\text { 19 DE NOVIEMBRE }\end{array}$ & 43.671 \\
\hline $\begin{array}{l}\text { DÍA DEL AÑO CON MENOS ACCESOS: } \\
\text { 23/01/1999 }\end{array}$ & 4.930 \\
\hline $\begin{array}{l}\text { HORA DE MÁXIMA CONSULTA } \\
\text { DESDE EL INICIO DEL SERVIDOR: } \\
\text { 13 HORAS }\end{array}$ & 139.006 \\
\hline
\end{tabular}

\begin{tabular}{|c|c|c|}
\hline $\begin{array}{l}\text { HORA DE MENOS CONSULTA } \\
\text { DESDE EL INICIO DEL SERVIDOR } \\
6 \text { HORAS }\end{array}$ & & 4.239 \\
\hline $\begin{array}{l}\text { PAÍSES QUE MÁS NOS HAN VISITADO } \\
\text { DESDE EL INICIO DEL SERVIDOR }\end{array}$ & $\begin{array}{l}\text { ESPAÑA } \\
\text { USA } \\
\text { MÉXICO } \\
\text { FRANCIA } \\
\text { ARGENTINA } \\
\text { PORTUGAL }\end{array}$ & \begin{tabular}{r|}
320.210 \\
36.197 \\
27.584 \\
5.929 \\
5.038 \\
2.317
\end{tabular} \\
\hline $\begin{array}{l}\text { SECCIONES O BLOQUES DE } \\
\text { INFORMACIÓN MÁS VISITADAS } \\
\text { DESDE EL INICIO DEL SERVIDOR }\end{array}$ & $\begin{array}{l}\text { VELÁZQUEZ: } \\
\text { DO.CO.MO.MO.: } \\
\text { PLAN GENERAL DE } \\
\text { BIENES CULTURALES: } \\
\text { INTERVENCIONES } \\
\text { EXPERIMENTALES: }\end{array}$ & $\begin{array}{r}190.371 \\
6.311 \\
4.104 \\
3.537\end{array}$ \\
\hline $\begin{array}{l}\text { PÁGINAS MÁS VISITADAS DESDE } \\
\text { EL INICIO DEL SERVIDOR }\end{array}$ & $\begin{array}{l}\text { ÍNDICE WEBS } \\
\text { DE INTERÉS: } \\
\text { WEBS DE } \\
\text { BIBLIOTECAS: } \\
\text { PÁGINA INICIAL CENTRO } \\
\text { DE DOCUMENTACIÓN: } \\
\text { BUSCADORES DE } \\
\text { INFORMACIÓN: } \\
\text { İNDICE PLAN GENERAL DE } \\
\text { BIENES CULTURALES: } \\
\text { PÁGINA INICIAL CENTRO } \\
\text { DE FORMACIÓN: }\end{array}$ & $\begin{array}{l}5.715 \\
4.366 \\
3.556 \\
3.338 \\
3.068\end{array}$ \\
\hline
\end{tabular}

\title{
El web de Córdoba, Ciudad Histórica Patrimonio de la Humanidad de España
}

En Internet, podemos encontrar información sobre muchas ciudades, enfocadas y reflejadas de maneras muy diversas, según sea el autor, el objetivo, y el público al que va dirigida. Normalmente, la información que encontramos es muy variada, ya que puede tratarse tanto desde un punto de vista meramente turístico, gastronómico, hotelero, artesanal o comercial, como desde un enfoque histórico-artístico, estableciendo unas rutas o itinerarios por la ciudad y sus alrededores, $y$ mostrando fotografías de sus monumentos $y$ lugares más emblemáticos, así como planos y vistas aéreas.

En esta línea, encontramos el Web de Córdoba Ciudad Histórica Patrimonio de la Humanidad de España. Esta web está relacionada con otras de las mismas características dedicadas al resto de ciudades de España declaradas Patrimonio de la Humanidad. Forma parte de una web principal, cuyo objetivo es establecer un vínculo entre todas ellas y potenciar el conocimiento cultural y las visitas a las mismas. Estas son: Ávila, Cáceres, Cuenca, Salamanca, Santiago de Compostela, Segovia y Toledo.

Realiza un viaje por todas ellas, a través de distintas rutas que pretenden unificar los aspectos comunes entre las mismas. Así, podemos encontrar: "Ruta de las Ciudades", "Ruta de la Historia", "Ruta de las Culturas", "Ruta de los Vestigios", "Ruta de las Eternidades", "Ruta de las Leyendas", "Ruta de las Razas", "Ruta de la Naturaleza", "Ruta de la Diversidad", "Ruta de los Nombres", "Ruta del Presente", y "Ruta de las Tradiciones".
Elegimos "Ruta de las Ciudades", y comenzamos el recorrido por la web, que nos muestra inicialmente un resumen de los distintos accesos que encontraremos a continuación y que recogen elementos del conjunto histórico de la ciudad. Todo ello siguiendo la línea de un itinerario o ruta turístico-cultural sin ningún orden aparente, y acompañado de un plano de la ciudad, donde vemos reflejados los monumentos y sitios de mayor interés artístico, así como de la dirección y teléfonos de contacto del Ayuntamiento de la ciudad.

Dichos accesos son los siguientes:

Mezquita de Córdoba, y Vista general de la Mezquita y La Catedral, donde encontramos información sobre la fecha de su creación, de 


\section{Actividades, productos y servicios}

sus artífices, metros cuadrados, así como una descripción artística de algunos de sus elementos y una propuesta de itinerario por la misma. En la vista aérea, vemos detalles sobre la construcción de la catedral en su interior, así como otras curiosidades históricas.

Fuentes de la Ciudad, presenta dos fotografías de la Fuente de la Calahorra y de la Fuente "de la piedra escrita", esta última acompañada de unos escasos datos históricos.

Calles y Patios, realiza un recorrido por el casco histórico de Córdoba, pasando desde la escultura de Maimónides o de Séneca en la Puerta de Almodóvar, hasta la de Averroes junto a la muralla. Igualmente, nos invita a pasear por el Barrio de la Judería, para desembocar en los famosos patios cordobeses a los que dedica dos amplias fotografías, con una descripción de sus forjas y flores, así como de la tradicional fiesta que en ellos se celebra en el mes de Mayo, ya sea en patios de conventos, palacios, monumentos, como en los populares donde suelen vivir varias familias.

Panorámica de Córdoba, nos muestra una fotografía del conjunto histórico de Córdoba, detallando la fecha de su declaración el 17 de Diciembre de 1994. En este punto existe un enlace con el siguiente.

Puente romano sobre el Guadalquivir, con una fotografía del mismo, presenta datos históricos de su construcción, así como de la devoción de los cordobeses por la escultura de San Rafael que la preside.

Puerta de San Miguel o de Al-Hakan II, con una amplia fotografía, muestra detalles de esta puerta, fruto de la aportación del califa que le da nombre. Enlaza con la información general de la Mezquita.

Torre de la Calahorra, con una breve información sobre su construcción en época medieval, informa de que hoy en día alberga al museo de la ciudad.

Catedral de Córdoba, con dos fotografías del interior, y de un detalle de la fachada respectivamente, aporta datos de su construcción en época cristiana por Carlos $V$, de los distintos artistas que intervinieron, así como detalles de su estilo.

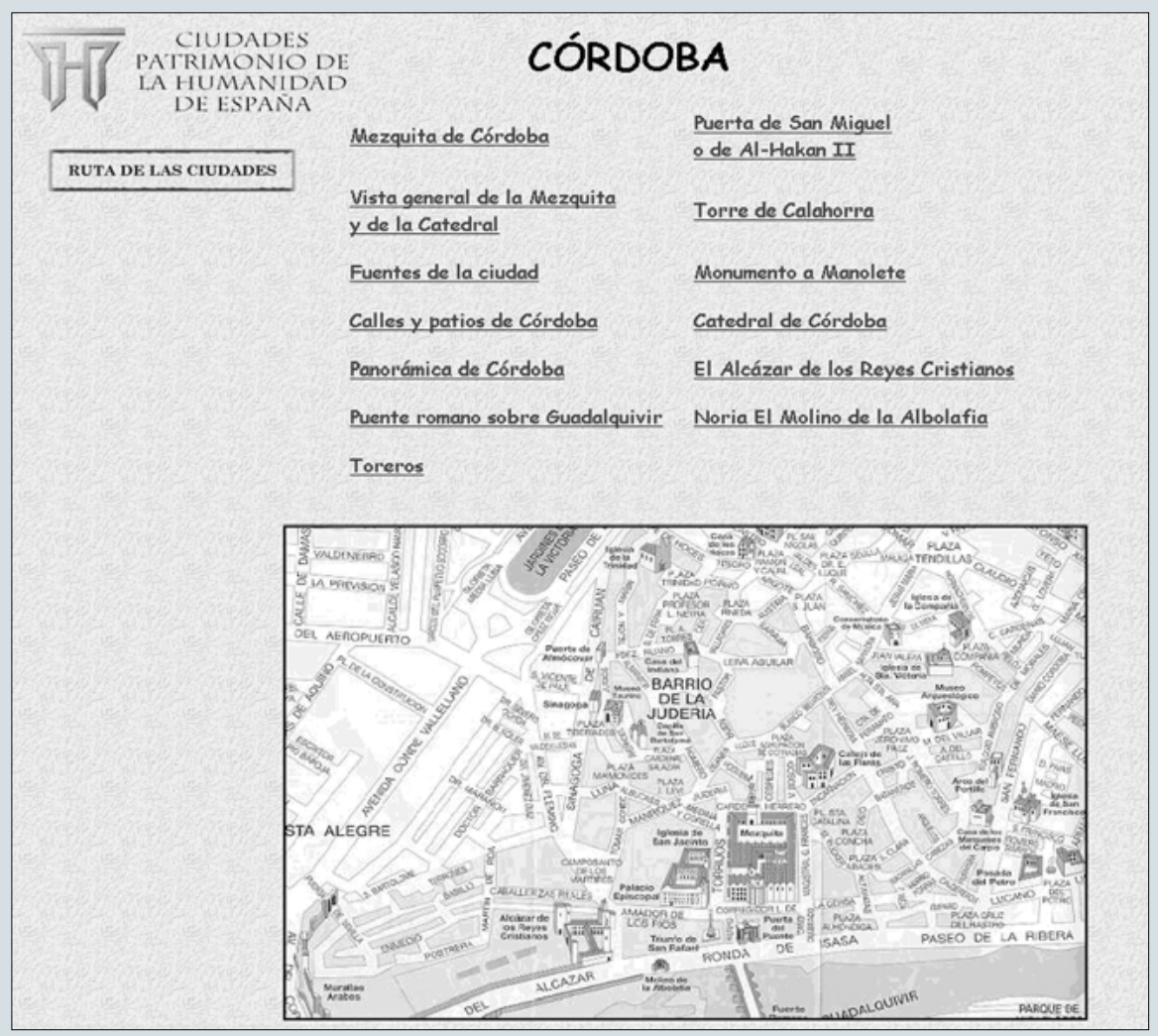

El Álcázar de los Reyes Cristianos: curiosamente, la información acerca de este monumento se presenta únicamente en inglés, quizás por error. Todo va en la misma línea que los puntos anteriores, mostrando aspectos histórico- artísticos de su construcción así como de su entorno.

Noria El Molino de la Albolafia, construido en época árabe, y mandado detener por Isabel la Católica por el ruido que producía.

Monumento a Manolete, muestra detalles de su ubicación, así como de los distintos actos que se celebraron en 1997, con motivo del 50 aniversario de su muerte.

Toreros, último punto dedicado al Museo Taurino de Córdoba, creado en el siglo XVI.

En conclusión, lo que cabe destacar de esta web son sus fotografías de gran calidad y definición, por encima de lo conciso de sus textos. Igualmente, la amplitud de los distintos aspectos que trata, ya sean de interés artístico, histórico, antropológico, o meramente anecdótico. Consigue en cierto modo el concepto de ruta, y ofrece la información suficiente como para hacerse una idea de lo que se debe conocer de esta ciudad.

Finalmente, destacar el acierto de su navegabilidad en español y en inglés y de su conexión con el resto de las ciudades españolas declaradas Patrimonio de la Humanidad.

Web principal Ciudades Patrimonio de la Humanidad de España:

http://www.cyberspain.com/ciudades-patrimonio

Web de Córdoba:

http://www.cyberspain.com/ciudades-patrimonio/ cordoba.htm

Susana Limón Rodríguez Centro de Documentación 